Acta Cryst. (2002). A58 (Supplement), C152

\section{3,5-DINITROBENZAMIDE: A NEW LIGAND FOR THE CREATION OF NOVEL SUPRAMOLECULAR ASSEMBLIES}

V.R. Pedireddi J. Prakasha Reddy K. Arora

National Chemical Laboratory Division of Organic Chemistry Pashan Road PUNE MAHARASHTRA 411008 INDIA

Crystal engineering of supramolecular assemblies in the solid state through the conversion of intermolecular interactions, such as hydrogen bonds formed between the specific functional groups, gained much popularity in recent times. In this respect, employment of molecular species in the form of ligands is a new modular approach for the synthesis of targeted supramolecular assemblies. For instance, 3,5-dinitrobenzoic acid, 4,4'-bipyridyl etc. have been shown to form a variety of assemblies with appropriate receptors. In this connection, amide moiety based assemblies are not well known despite the fact that amides form two distinct hydrogen bond patterns: cyclic and catemeric hydrogen bonds. Hence, we have taken up the study of design and synthesis of supramolecular assemblies of 3,5-dinitrobenzamide. To begin with, its threedimensional crystal structure has been determined by crystallizing from various solvents and it has been observed that, from low polarity solvents like methanol, chloroform etc., the amide crystallizes on its own but, from high polar solvents like dimethylsulfoxide (DMSO), it forms an adduct. An interesting feature is that, from a mixture of DMSO and benzene solvents, the amide forms a crystal structure with disordered DMSO molecules, retaining all other features of the DMSO adduct. In continuation, we have synthesized a variety of supramolecular assemblies of 3,5-dinitrobenzamide with molecules like phenazine, 3,5-dinitrobenzoic acid, 4,4'-bipyridyl, etc. In these adducts, the amide adopts different types of hydrogen bonding patterns - while the cyclic hydrogen bonding predominates the structural features in the complex with 3,5-dinitrobenzoic acid forming a channel structure, catemeric hydrogen bonds influence the molecular arrangement in the assembly with phenazine forming a herringbone type structure.

\section{Keywords: CRYSTAL ENGINEERING ORGANIC MOLECULES} AMIDE LIGANDS

\section{Acta Cryst. (2002). A58 (Supplement), C152 \\ SYNTHESIS AND STRUCTURES OF COMPLEXES OF BENZENEPOLYCARBOXYLIC ACIDS WITH FIRST ROW TRANSITION METALS}

N.C. Martin W Clegg

University of Newcastle Upon Tyne Chemistry Department Bedson Building NEWCASTLE UPON TYNE NE1 7RU UK

Compounds with polymeric network structures have a tendency to form powders rather than single crystals because of their low solubility on formation. By altering the growing conditions it is possible to induce slower crystallisation and then study the structure through single crystal X-ray diffraction experiments.

Techniques of vapour diffusion and diffusion through silica gel have been developed to improve the quality and size of crystals for single crystal X-ray diffraction experiments. The first method uses the medium of air to separate the reaction constituents and the second uses silica gel as a barrier between the reagents.

Benzenepolycarboxylic acids have been reacted with first row transition metals to form polymeric 3D networks. Deprotonation of pyromellitic acid $(1,2,4,5$ benzenetetracarboxylic acid) gives anions with 1-4 negative charges, which can act as multidentate ligands. Deprotonation of mellitic acid (1,2,3,4,5,6benzenehexacarboxylic acid) gives anions of 1-6 negative charges, which can act as multidentate ligands. There is potential for supramolecular products with these anions linking metal centres, with the added possibilities of hydrogen bonding interactions when the acids are not fully deprotonate.

The results include complexes of copper and cobalt with a variety of modes of coordination of the polycarboxylic anion and the incorporation of bases either as additional ligands or in the protonated form as counter-ions. Structures are usually polymeric arrays with units linked by covalent bonding and hydrogen bonding.

Keywords: SUPRAMOLECULAR HYDROGEN BONDS BENZENECARBOXYLIC ACIDS
Acta Cryst. (2002). A58 (Supplement), C152

TWO PAIRS OF 4-AMINOAZOXYBENZENE POLYMORPHS

J. Zaleski K. Ejsmont A. Doma'nski J.B. Kyzio

Institute of Chemistry University of Opole Oleska 48 OPOLE 45-052 POLAND

The acid catalysed transformation of azobenzenes into azoxybenzenes is well known as the Wallach rearrangement. This oxidation provided the mixture of two azoxy compounds ( $\alpha$ and $\beta$ ). We prepared two isomeric trans-4aminoazoxybenzenes and compared their geometries. The amino derivatives have been selected since the amino group may be considered as a probe, indicative of the intermolecular interactions of the azoxy group with the aromatic rings. Their influence of the amino group bonded to the ring, on the oxidised and unoxidised sides of the azoxy bridge, should provide some information on the electronic properties of the azoxy group. The question is essential in the investigations of the mechanism of the Wallach rearrangement. The 4-amino-azobenzene has been oxidised to the corresponding azoxybenzenes. The isomers were crystallised from benzene-nheptane, they are both monoclinic (form I). By the recrystallisation from the ethanol-water solutions two other isomers of both compounds have been obtained (orthorhombic, form II). The molecule of the $\alpha$ isomer (form I) is almost planar, whereas Ar-N bond torsion angles in form II are much higher. The geometries of the $\beta$ isomers are similar in both forms but they are much different than the $\alpha$ isomers. The non-substituted phenyl ring is twisted in respect to the NNO plane of ca. $50^{\circ}$, whereas the substituted ring is almost coplanar with the NNO plane. Molecules of both isomers in both phases are arranged in crystal structure in chains connected with each other by weak N$\mathrm{H}$...O and $\mathrm{N}-\mathrm{H} . . . \mathrm{N}$ hydrogen bonds.

\section{Keywords: AZOXYBENZENE, WALLACH REARRANGEMENT, ISOMERS}

\section{Acta Cryst. (2002). A58 (Supplement), C152 \\ PRECURSORS FOR PREPARATION OF NOBEL METAL PHASES WITH A 2:1 RATIO}

K.V. Yusenko ${ }^{1}$ S.A. Gromilov ${ }^{2}$ I.A. Baidina ${ }^{2}$ S.V. Korenev ${ }^{2}$

${ }^{1}$ Novosibirsk State University Pirogova Str. 2 NOVOSIBIRSK 630090 RUSSIA ${ }^{2}$ Institute of Inorganic Chemistry, Siberian Branch of Russian Academy of Sciences

The paper reports synthesis and the crystal structure of complexes $\left[\mathrm{M} 1\left(\mathrm{NH}_{3}\right)_{5} \mathrm{Cl}\right] 2\left[\mathrm{M}_{2} \mathrm{Cl}_{6}\right] \mathrm{Cl}_{2}$, where $\mathrm{M} 1=\mathrm{Rh}, \mathrm{Ir} ; \mathrm{M} 2=\mathrm{Pt}$, Ir. These compounds may be used as precursors for preparation of solid solutions of metals with a specified ratio $2: 1$. The complexes were prepared by slow crystallization from a solution. Several mmol of $\left[\mathrm{M} 1\left(\mathrm{NH}_{3}\right)_{5} \mathrm{Cl}\right] \mathrm{Cl}_{2}$ were sealed with $10 \mathrm{ml}$ of $0.1 \mathrm{M}$ $\mathrm{HCl}$ solution containing an equimolar amount of $\left(\mathrm{NH}_{4}\right)_{2}\left[\mathrm{M}_{2} \mathrm{Cl}_{6}\right]$. Octahedral crystals formed after several days. Crystal structure data for $\left[\mathrm{Rh}\left(\mathrm{NH}_{3}\right)_{5} \mathrm{Cl}\right] 2\left[\mathrm{MCl}_{6}\right] \mathrm{Cl}_{2} \quad(\mathrm{M}=\mathrm{Pt}, \quad \mathrm{Ir})$ are given in $[1,2]$, and for $\left[\operatorname{Ir}\left(\mathrm{NH}_{3}\right)_{5} \mathrm{Cl}\right] 2\left[\mathrm{PtCl}_{6}\right] \mathrm{Cl}_{2}$ in [3]. Crystallographic characteristics for $\left[\operatorname{Ir}\left(\mathrm{NH}_{3}\right)_{5} \mathrm{Cl}\right] 2\left[\mathrm{IrCl}_{6}\right] \mathrm{Cl}_{2}$ are $a=11.221(2), b=7.912(2), c=13.427(3), \beta=$ 99.62(3), $\mathrm{V}=1175.3$, Space group $\tilde{N} 2 / \mathrm{m}, \mathrm{Z}=2$, Dx $=3.113 \mathrm{~g} / \mathrm{cm} 3$. All phases listed are isostructural and are built of discrete complex cations $\left[\mathrm{M} 1\left(\mathrm{NH}_{3}\right)_{5} \mathrm{Cl}\right]^{2+}$, complex anions $\left[\mathrm{M} 2 \mathrm{Cl}_{6}\right]^{2-}$ and $\mathrm{Cl}^{-}$anions. Geometric characteristics of coordination polyhedra are not virtually different from those for $\left[\mathrm{M} 1\left(\mathrm{NH}_{3}\right)_{5} \mathrm{Cl}\right] \mathrm{Cl}_{2}$ and $\left(\mathrm{NH}_{4}\right)_{2}\left[\mathrm{M} 2 \mathrm{Cl}_{6}\right]$. The $\left[\mathrm{M}_{2} \mathrm{Cl}_{6}\right]^{2-}$ anions have $2 / \mathrm{m}$ symmetry and are surrounded by six cations to form a distorted octahedron. The $\mathrm{Cl}$ anions lie in the symmetry plane $\mathrm{m}$ and the environment is a distorted tetrahedron of four cations. The $\left[\mathrm{M} 1\left(\mathrm{NH}_{3}\right)_{5} \mathrm{Cl}\right]^{2+}$ cations are located in the symmetry plane $\mathrm{m}$.

We compared the structures of four compounds mentioned and analyzed hydrogen bonds and a general packing motif.

References

[1] K.V.Yusenko, S.A.Gromilov, S.V.Korenev et al., Zh. Strukt. Khim. (Russ. Transl.), 2002, in press.

[2] S.A.Gromilov, I.A.Baidina, K.V.Yusenko, S.V. Korenev. Abstr. of the XXth Int. Chugaev Conference on Coord. Chem. Rostov-on-Don, 2001, P. 190-191.

[3] E.Garnier, Acta. Cryst., C49, (1993), P. 578-580. 